\title{
ZASTOSOWANIE METODY ELEMENTÓW SKOŃCZONYCH W ANALIZIE NUMERYCZNEJ LOŻYSK TOCZNYCH WIEŃCOWYCH
}

Streszczenie: W artykule przedstawiono metodykę budowy modeli MES łożysk wieńcowych. Zaproponowano zalecenia dotyczące sposobu modelowania kontaktu między elementami tocznymi a bieżniami. Uwzględniono zagadnienia związane $\mathrm{z}$ odpowiednim podziałem pierścieni łożyska na elementy skończone, sposób modelowania śrub mocujących łożysko do struktur zabudowy, charakterystyki materiałów. Przeprowadzone analizy zostały oparte na podstawie systemu FEMAP.

Słowa kluczowe: metoda elementów skończonych, łożyska wieńcowe, nośność łożysk.

\section{Wprowadzenie}

Ze względu na szybki rozwój programów wspomagających obliczenia numeryczne, wzrasta zapotrzebowanie na inżynierów ze znajomością metod numerycznych i metody elementów skończonych. Programy wykorzystujące metodę elementów skończonych są szeroko wykorzystywane w przemyśle budowlanym, ciężkim oraz przemyśle motoryzacyjnym. Pomimo, iż istnieje wiele aplikacji wspomagających obliczenia numeryczne, to znaczna liczba elementów w nich wykorzystywanych, ma wspólne właściwości i podobne zastosowania. Elementy klasyfikuje się z uwagi na wymiar elementu skończonego, kształt geometryczny, rząd funkcji kształtu, stopnie swobody w węźle i przeznaczenie od rodzaju analizy (RUSIŃSKI E, SMOLNICKI T. 2010).

W niniejszym rozdziale zostaną omówione wskazówki dotyczące obliczania łożysk tocznych wieńcowych z wykorzystaniem metody elementów skończonych.

\section{Budowa numerycznych modeli MES łożysk wieńcowych}

Dla danego łożyska wieńcowego można opracować różne modele matematyczne w zależności od przyjętych założeń, poczynionych uproszczeń oraz sposobu opisu zachodzących procesów fizycznych. Uproszczenia, poczynione przy

${ }^{1} \mathrm{dr}$ inż., Politechnika Czestochowska, Wydział Zarządzania, Katedra Inżynierii Produkcji i Bezpioeczeństwa, e-mail: krynke@ zim.pcz.pl 
opracowywaniu modelu, ułatwiają jego opis, jednakże mają one wpływ na dokładność poszukiwanego rozwiązania. Daleko idące uproszczenia mogą spowodować pominięcie istotnych cech układu rzeczywistego, natomiast zbyt złożony model matematyczny może spowodować błędy w rozwiązaniu ze względu na skomplikowany proces obliczeniowy (KRYNKE M., BORKOWSKI S. 2013).

Rozwiązując zadanie MES, należy utworzyć model matematyczny zawierający następujące elementy (ZIENKIEWICZ O., TAYLOR R. L1991):

- opis powierzchni ograniczającej badany obszar, wewnątrz którego poszukujemy rozwiązania,

- warunki brzegowe na powierzchni ograniczającej badany obszar oraz warunki ciągłości,

- wymuszenia, czyli pewne zewnętrzne przyczyny wywołujące skutki określone równaniem stanu.

Budowa numerycznych modeli obliczeniowych łożysk wieńcowych i ich rozwiązanie przy pomocy MES, składa się z następujących etapów:

- zbudowanie modelu obliczeniowego - polega na podziale rozpatrywanego obszaru na elementy wraz z przyjęciem ich typu i parametrów węzłowych,

- analiza poszczególnych elementów - polega na wyliczeniu macierzy sztywności (zagadnienia mechaniki) wraz $\mathrm{z}$ przyjęciem odpowiednich funkcji interpolacyjnych, które służą do przybliżonego określania pola poszukiwanych wartości i stanowią o zbieżności procesu obliczeniowego,

- ustalenie warunków brzegowych - polega na takiej modyfikacji globalnej macierzy sztywności, aby stała się ona macierzą nieosobliwą, tzn. przemieszczenia nie mogą być niezależne od obciążeń. Warunek ten można spełnić, określając warunki podparcia konstrukcji oraz eliminując zbędne stopnie swobody, a osiąga się to przez wpisanie zer w wiersze oraz kolumny odpowiadające węzłom o znanych potencjałach i jedynki na głównej przekątnej,

- rozwiązanie globalnego układu równań - czyli wyznaczenie niewiadomych przy wykorzystaniu pasmowości i symetrii globalnej macierzy sztywności,

- prezentacja wyników - polega na ich wyświetleniu na ekranie monitora lub wydrukowaniu w formie umożliwiającej ich późniejszą interpretację.

Wszystkie wyżej wymienione etapy zazwyczaj rozdzielone są między trzy moduły programu (RUSIŃSKI E. $\mathrm{i}$ in. 2000):

- preprocesor (służy m.in. do importu lub przygotowania geometrii, doboru rodzaju elementów skończonych, dyskretyzacji kontinuum, a także przyłożenia warunków brzegowych), 
- solver (moduł przeznaczony do budowy oraz rozwiązania układu równań, na podstawie którego uzyskuje się poszukiwane wartości danych wielkości fizycznych),

- postprocesor (moduł służący do prezentacji oraz wspomagania interpretacji uzyskanych wyników).

\section{Podzial pierścieni lożyska na elementy skończone}

Wyodrębnienie elementów w obszarze, w którym poszukujemy rozwiązania zadania, jest bardzo ważnym etapem $\mathrm{w}$ tworzeniu modelu obliczeniowego MES. Sposób dyskretyzacji zależy od geometrii obszaru, własności fizycznych, pewnych ogólnych przesłanek co do wyników rozwiązania, a także oczekiwanej efektywności obliczeń.

Sposób dyskretyzacji obszaru warunkuje liczbę niewiadomych, wielkość i kształt elementów, a to wpływa na dokładność rozwiązania zadania. Elementy skończone powinny być dobrze proporcjonalne. Idealne elementy objętościowe to regularny czworościan i sześcian. Elementy do pewnego stopnia mogą być deformowane. Wykonanie dobrej siatki dla złożonych kształtów jest zadaniem trudnym i zazwyczaj wymaga wielu prób z wykorzystaniem różnych narzędzi generowania siatki. Ocena jakości siatki wykonywana jest automatycznie (KRYNKE M., BORKOWSKI S., SELEJDAK J. 2014, KRYNKE M. 2015.).

Podział pierścieni łożyska wieńcowego na elementy skończone w przekroju poprzecznym narzucony jest przez ich kształty, natomiast wzdłuż obwodu łożysk jest zdeterminowany rozmieszczeniem części tocznych. Należy również zachować regularność elementów skończonych w poszczególnych segmentach po obwodzie dyskretyzowanych pierścieni. Współpraca pierścieni łożyska między sobą, realizowana jest przez zastępcze elementy liniowe (elementy prętowe lub superelementy) pośredniczące $\mathrm{w}$ przenoszeniu obciążeń $\mathrm{z}$ pierścienia związanego $\mathrm{z}$ nadwoziem na pierścień pozostający w kontakcie $\mathrm{z}$ siedziskiem podwozia maszyny roboczej. Przykładowy numeryczny model obliczeniowy dla łożyska wałeczkowego krzyżowego przedstawiono na rysunku 1.

Aby wyeliminować różne zagęszczenie siatki elementów skończonych po obwodzie pierścieni łożyska wykorzystuje się generator siatki tworzonej z wyciągnięciem. Generator tworzy siatkę objętościową w warstwach domeny utworzonej przez wyciągniecie. Elementy objętościowe są graniastosłupami lub sześciościanami w zależności od kształtu elementu powierzchniowego (trójkąty lub prostokąty) na powierzchni bazowej. 


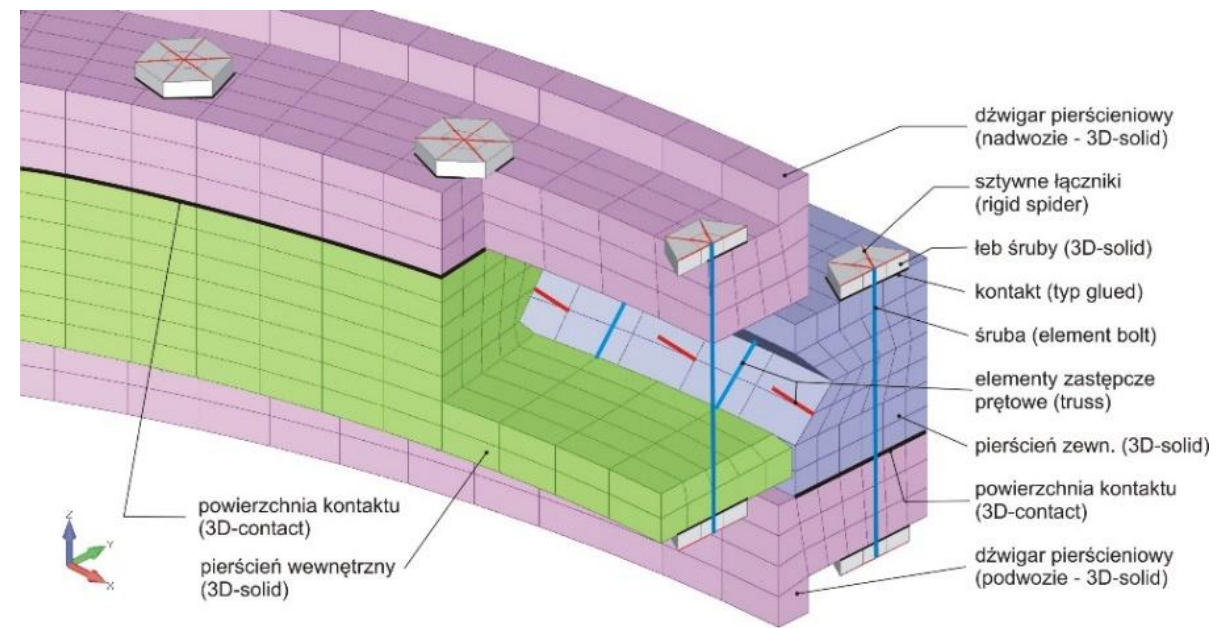

Rys. 1. Siatka modelu mes tożyska waleczkowego krzyżowego

Źródto: opracowanie własne

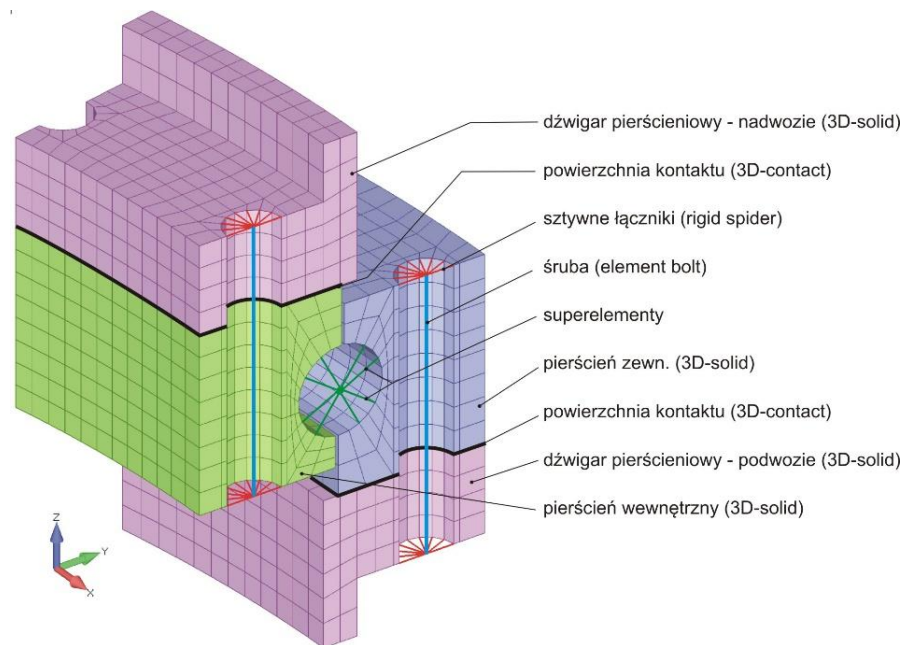

Rys. 2. Siatka modelu mes sektora elementarnego łożyska kulkowego czteropunktowego Źródto: opracowanie własne

Podział pierścieni łożyska na elementy skończone, w którym uwzględnia się otwory pod śruby mocujące, sprawia pewne trudności w uzyskaniu regularnej siatki MES, ze względu na skomplikowaną postać modelu geometrycznego (rys. 2). Aby uprościć model geometryczny, należy wydzielić sektor elementarny pierścienia pomiędzy sąsiednimi śrubami i podzielić go na elementarne bryły składowe np. tak jak uczyniono to na rys. 3 . 
a)

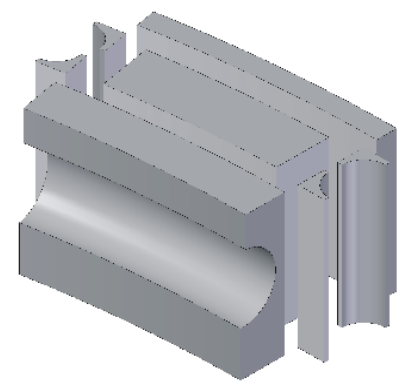

b)

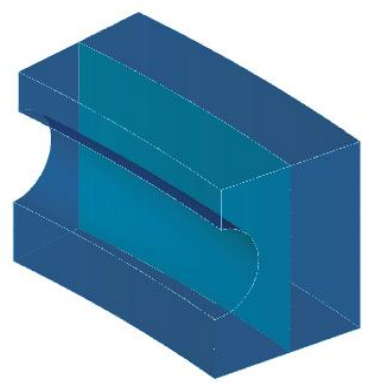

Rys. 3. Model geometryczny pierścienia tożyska: a) z otworami pod śruby mocujące, b) z pominięciem otworów pod śruby

Źródto: opracowanie własne

Następnie można wykorzystać właściwości siatki „topologicznej”. Mechanizm tworzenia siatek regularnych wykorzystuje topologiczne właściwości powierzchni bryły. Pozwala on na wykonanie siatki na powierzchniach prostokątnych elementami prostokątnymi (lub czworokątnymi) oraz $\mathrm{w}$ objętościach równoległościennych elementami prostopadłościennymi (rys. 4). W tym algorytmie kontur powierzchni dzielony jest na cztery linie, z których linie naprzeciwległe mają taką samą liczbę elementów. Powierzchnia dzielona siatką jest więc topologicznie równoważna prostokątowi. Objętość dzielona taką siatką jest topologicznie równoważna równoległościanowi.
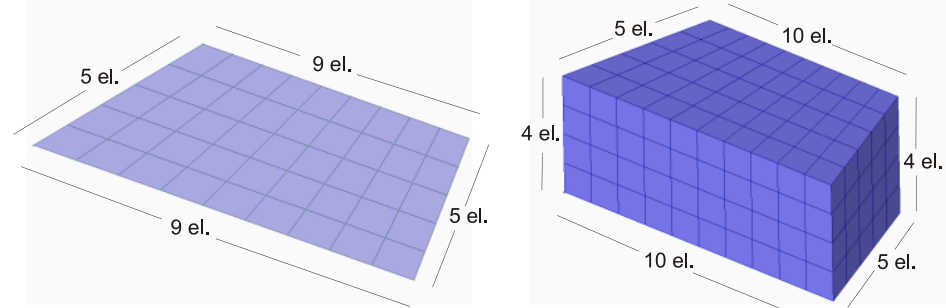

\section{Rys. 4. Siatka „topologiczna”: a) na powierzchni prostokątnej, b) w objętości równoleglościennej}

Źródto: opracowanie własne

Optymalnym rozwiązaniem dla uniknięcia błędów jest podział jednego sektora elementarnego tworząc pierścieniowe wzorce równe liczbie śrub mocujących pierścień łożyska, oraz połączeni pokrywających się węzłów. 
Pierścienie łożysk są mocowane do siedzisk maszyny zespołem śrub mocujących. Siedziska łożysk wieńcowych najczęściej mają postać grubościennych dźwigarów pierścieniowych otwartych. Śruby zastępuje się elementami belkowymi, do których można przyłożyć napięcie wstępne w postaci siły odpowiadającej sile napięcia śrub mocujących łożysko do struktur zabudowy (KRYNKE M. 2016). Łby śrub modeluje się wykorzystując 8-węzłowe elementy bryłowe. Dyskretyzacja pierścieni łożyska jest zdeterminowana podziałką części tocznych. Aby uniknąć dodatkowego zagęszczania siatki w miejscach rozmieszczenia śrub wykorzystuje się mechanizm sklejania siatki (mesh glueing) na powierzchniach składowych brył modelu geometrycznego. Umożliwia on generowanie siatki o różnej gęstości w poszczególnych segmentach modelowanej bryły (lub użycie do ich dyskretyzacji elementów o różnej liczbie węzłów) (ADINA 2007). Zabieg ten upraszcza model, pozwala w łatwy sposób osiągnąc dowolne rozmieszczenie śrub mocujących z uwagi na brak konieczności odpowiedniego rozmieszczenia ich węzłów z węzłami pierścieni zabudowy w celu ich połączenia. W rezultacie pierścienie nie muszą być podzielone zgodnie z kryterium rozmieszczenia śrub mocujących. Zaletą tej metody jest stosowanie takiej samej liczby elementów

$\mathrm{Na}$ powierzchniach kontaktu pierścieni łożyska z pierścieniami konstrukcji wsporczych należy zdefiniować powierzchnie kontaktu.

\section{Modelowanie części tocznych}

W łożyskach tocznych wieńcowych występuje duża liczba par kontaktowych na powierzchniach styku elementów tocznych z bieżniami łożyska. Budowa pełnego modelu MES łożyska z uwzględnieniem kształtu części tocznych i zdefiniowaniem zagadnienia kontaktowego każdej $\mathrm{z}$ nich prowadzi zazwyczaj do osobliwości macierzy sztywności, co z kolei uniemożliwia rozwiązanie zadania. W celu uproszczenia procedur obliczeniowych i tym samym uzyskania optymalnych czasów obliczeń części toczne $\mathrm{w}$ modelach MES zastępuje się jednowymiarowymi elementami skończonymi (elementy liniowe). Jako zastępcze elementy liniowe w łożyskach wieńcowych stosuje się:

- elementy prętowe o odpowiedniej jednostronnej nieliniowej charakterystyce materiałowej naprężenie - odkształcenie (rys. 5) - stosowane do łożysk wałeczkowych,

- elementy specjalne (superelementy) (rys. 6), przeznaczone głównie do łożysk kulkowych, bazujące na superelemencie zaproponowanym przez Smolnickiego w pracy (SMOLNICKI T. 2002). 


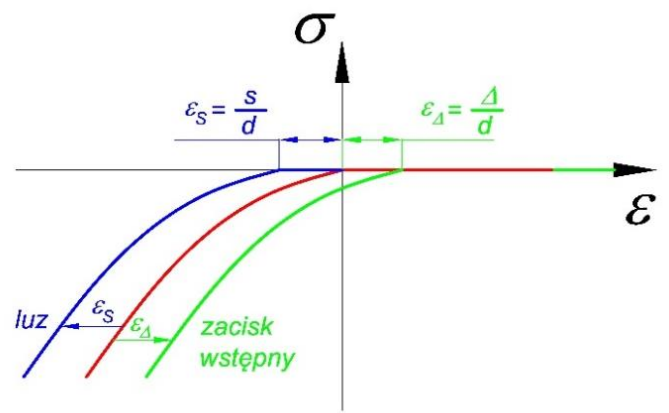

Rys. 5. Charakterystyka naprężenie - odkształcenie elementu prętowego zastępującego waleczki w modelach MES tożysk

Źródło: opracowanie własne

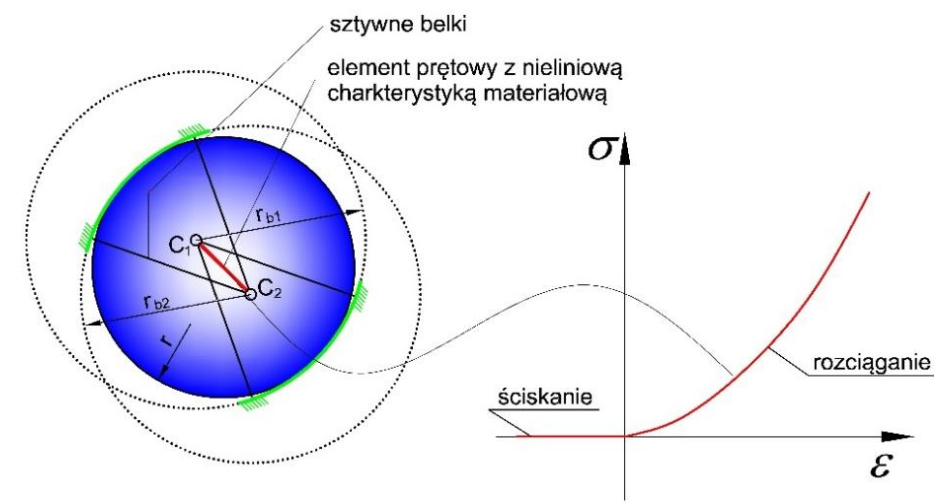

Rys. 6. Superelement z nieliniowa asymetryczną charakterystyka materialową dla kulek Źródło: opracowanie własne

Superelement składa się z układ dwóch par elementów belkowych połączonych przegubowo $\mathrm{w}$ miejscu położenia środków krzywizn bieżni łożyska $\mathrm{w}$ ich przekroju osiowym $\mathrm{z}$ pojedynczym elementem prętowym. Pozostałe końce elementów belkowych są połączone $\mathrm{z}$ węzłami siatki pierścieni łożyska. Element prętowy ma ściśle określoną długość i wartość przekroju poprzecznego oraz odpowiednio zdefiniowaną charakterystykę materiałową $\sigma(\varepsilon)$ (KANIA L. 2006) i pełni rolę nieliniowej sprężyny. Założony luz osiowy $s$ łożyska lub ewentualny zacisk wstępny $\Delta$ w modelach MES zdefiniowano poprzez przesunięcie charakterystyki materiałowej zgodnie z kierunkiem jak na rysunku 5 . 
Superelement pozwala określić przemieszczenia rzeczywistego elementu tocznego poddanego działaniu obciążenia zewnętrznego przekazywanego na części toczne za pośrednictwem pierścieni łożyskowych, a w szczególności zmiany kąta działania łożysk kulkowych, co trudno jest uzyskać innymi metodami.

\section{Warunki brzegowe}

Na rysunku 7 przedstawiono kompletny model numeryczny łożyska wieńcowego kulkowego jednorzędowego. Do analizy przyjęto połowę łożyska i pierścieni zabudowy. Do modelu wprowadzono odpowiednie warunki brzegowe wynikające z symetrii modelu. Zdefiniowano odpowiednie powierzchnie kontaktu pomiędzy pierścieniami łożyska i pierścieniami zabudowy.

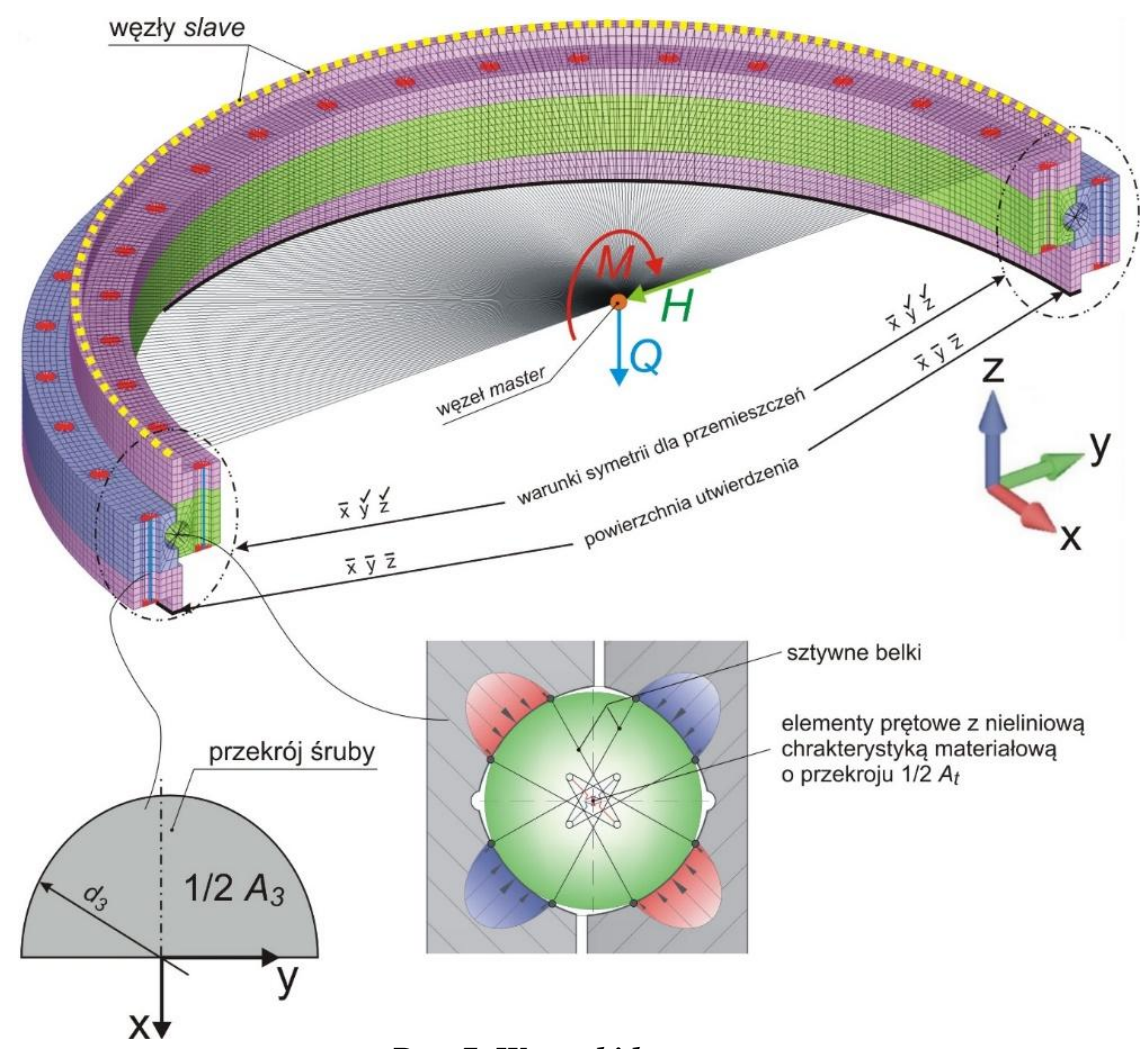

Rys. 7. Warunki brzegowe

Źródto: opracowanie własne. 
Śruby mocujące łożysko znajdujące się w płaszczyźnie symetrii łożyska zostały zamodelowane w postaci elementów belkowych o przekroju połowy rdzenia śruby $A_{3}$ (rys. 7). Do skrajnych śrub o przekroju $1 / 2 A_{3}$ przyłożono napięcie wstępne o wartości $1 / 2 F_{M}$ napięcia wstępnego śruby mocującej. Podobnie w elementach prętowych zastępujących węzłowe części toczne, przyjęto połowę ich przekroju $A_{t}$.

Dolną powierzchnię pierścienia zabudowy, do którego jest mocowany zewnętrzny pierścień łożyska, podparto sztywnie. Na górnej powierzchni pierścienia zabudowy, do którego jest mocowany pierścień wewnętrzny łożyska nałożono sztywne powiązania między węzłami znajdującymi się na tej powierzchni (węzły slave) a węzłem centralnym (węzeł master) znajdującym się w środku ciężkości węzłów slave. Powstałe $\mathrm{w}$ ten sposób pary węzłów tworzą „sztywną pajęczynę”, której punktem centralnym jest węzeł główny, do którego przykładane jest obciążenie zewnętrzne w postaci siły skupionej i momentu skupionego. Kiedy model doznaje deformacji węzły slave są zmuszone do przesunięcia i obrotu $\mathrm{w}$ ten sposób by odległość między węzłami slave i węzłem master pozostała stała i obroty węzłów slave są takie same jak odpowiednie obroty na węźle głównym. Przyłożone w ten sposób obciążenie, wywołuje obciążenie łożyska zadanym momentem wywrotnym $M$, siłą osiową $Q$ i siłą promieniową $H$ (1.7). Proces obliczania nośności łożyska odbywa się iteracyjnie. Dla założonego obciążenia zewnętrznego przeprowadza się obliczenia modelu numerycznego i określa rozkład obciążenia wewnętrznego w łożysku. Obliczenia prowadzi się do osiągnięcia wartości granicznego obciążenia części tocznych w jednym z rzędów obliczeniowych łożyska.

\section{Podsumowanie}

Zastosowanie metody elementów skończonych w numerycznych obliczeniach inżynierskich wspomaganych komputerowo pozwala na szybkie i relatywnie dokładne osiągnięcie wyników, których uzyskanie metodą analityczną byłoby bardzo trudne lub wręcz niemożliwe.

Wykorzystanie MES do zweryfikowania poprawności funkcjonowania danego wyrobu umożliwia krokową lub dokładną optymalizację jego wybranych cech już od wczesnych etapów rozwoju produktu. Uzyskuje się więc możliwość radykalnego skrócenia czasu trwania uruchomienia produkcji nowego wyrobu lub modyfikacji wyrobu już znajdującego się w produkcji.

Należy mieć na uwadze, że wyniki analiz MES opisują zachowanie się układu w sposób przybliżony, są zawsze obarczone pewnym błędem, który w przypadku poprawnego prowadzenia analizy CAE można uznać za pomijalnie mały. 
Modele obliczeniowe wieńcowych łożysk tocznych z uwagi na ich złożoność muszą podlegać różnego rodzaju uproszczeniom. Dotyczy to również obliczania nośności łożysk z wykorzystaniem metody elementów skończonych.

\section{Bibliografia}

1. RUSIŃSKI E, SMOLNICKI T. 2010. Rozwój metod obliczeniowych w budowie maszyn i pojazdów, Przegląd Mechaniczny nr 6. s.17-24.

2. ZiEnKiewicZ O. C., TAYLOR R. L1991. The finite element method. Vol. 1, Vol. 2. McGraw-Hill Book Company, London.

3. RUSIŃSKI E., CZMOCHOWSKI J., SMOLNICKI T. 2000. Zaawansowana metoda elementów skończonych $w$ ustrojach nośnych maszyn. Oficyna Wydawnicza Politechniki Wrocławskiej, Wrocław.

4. ADINA 2007. Theory and Modeling Guide. Volume 1: ADINA. ADINA R\&D, Inc., Watertown.

5. SMOLNICKI T. 2002. Fizykalne aspekty koherencji wielkogabarytowych łożysk tocznych i odkształcalnych konstrukcji wsporczych. Oficyna Wydawnicza Politechniki Wrocławskiej, Wrocław.

6. KANIA L. 2006. Modelling of rollers in slewing bearing calculations with the use of finite elements. Mechanism and Machine Theory, 41, 11: 1359-1376.

7. KryNKe M., BorkowsKi S. 2013. Metodyka budowania modeli obliczeniowych MES łożysk wieńcowych dotycząca dyskretyzacji pierścieni łożyska. Modelowanie Inżynierskie. $\mathrm{Nr}$ 49. s.40-46.

8. Krynke M., Borkowski S., SelejDAK J. 2014. Analysis of Influence of Bearing Clearance on the Static Carrying Capacity of Multi-row Slewing Bearings. Periodica Polytechnica Transportation Engineering. Vol. 42, s.43-48.

9. KrynKe M. 2015. The Dynamic State Monitoring of Bearings System. Production Engineering Archives. Vol. 6(1). s. 35-38.

10. KRYNKE M. 2016. Numerical analysis of bolts loading in slewing bearing. Czasopismo Techniczne Mechanika. s z.4-M (14). s.89-94. 